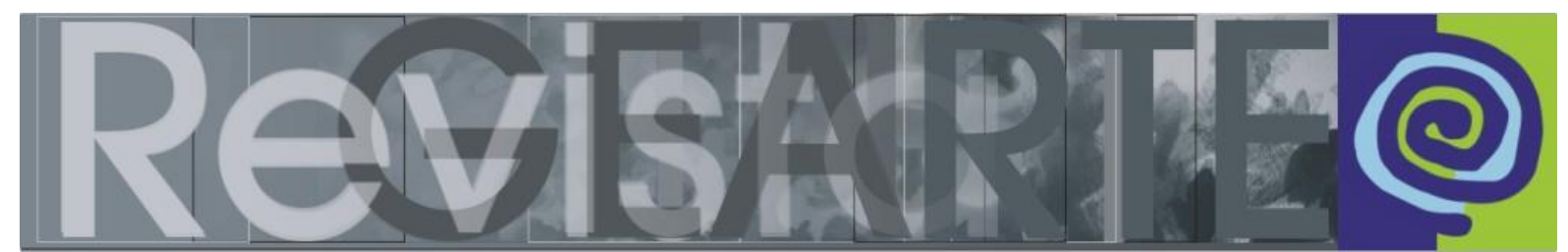

ISSN 2357-9854 | e-ISSN 2596-3198 (online)

\title{
Trabajo artesanal, artesanía e industrias creativas: reflexiones en torno a las transformaciones de la actividad sociocultural
}

\author{
Daniel Roberto Vega Torres \\ (Fundación Universitaria Juan de Castellanos, Tunja/Boyacá, Colombia)
}

\begin{abstract}
RESUMEN - Trabajo artesanal, artesanía e industrias creativas: reflexiones en torno a las transformaciones de la actividad sociocultural - El objetivo del artículo es desarrollar una crítica de la comprensión de la artesanía y del trabajo artesanal desde el desarrollo histórico capitalista. Para ello se realiza una primera reflexión entre la industria y el trabajo artesanal como parte de la organización técnica y política de los artesanos en el capitalismo industrial. Luego se desarrolla una reflexión sobre la Industria cultural y la artesanía, entendiendo las implicaciones sociales políticas y simbólicas que permiten reconocer la emergencia de la artesanía y del artesano. Después se complementa la reflexión mediante el análisis de las industrias creativas y la producción artesanal en la clasificación de ocupaciones actual. Al final se realizan reflexiones conceptuales y políticas que definen trayectorias de estudio e intervención.
\end{abstract}

PALABRAS CLAVE

Trabajo artesanal. Artesanía. Artesanos. Capitalismo. Creatividad.

RESUMO - Trabalho artesanal, artesanato e indústrias criativas: reflexões em relação às transformações da atividade sociocultural - $O$ objetivo do artigo é desenvolver uma crítica da compreensão do artesanato e do trabalho artesanal desde o desenvolvimento histórico capitalista. Nesse sentido se realiza uma primeira reflexão entre a indústria e o trabalho artesanal como parte da organização técnica e política dos artesãos no capitalismo industrial. Depois se apresenta uma reflexão sobre a indústria cultural e o artesanato, entendendo as relações sociais, políticas e simbólicas que oferecem reconhecimento do aparecimento do artesanato e do artesão como expressão cultural. Logo, se complementa a reflexão com a análise das indústrias criativas e a produção artesanal na atual classificação de ocupações. No final do artigo realizam-se reflexões conceituais e políticas que definem trajetórias do estudo e intervenção.

PALAVRAS-CHAVE

Trabalho artesanal. Artesanato. Artesãos. Capitalismo. Criatividade.

\begin{abstract}
Craft work, crafts and creative industries: reflections on the transformations of socio-cultural activity. - The objective of the article is to develop a critique of the understanding of crafts and craft work from the capitalist historical development. For this, a first reflection is made between industry and artisan work as part of the technical and political organization of artisans in industrial capitalism. Then a reflection is developed on the cultural industry and crafts, understanding the political and symbolic social implications that allow us to recognize the emergence of crafts and artisans. Then the reflection is complemented by analyzing the creative industries and artisan production in the current occupation classification. At the end, conceptual and political reflections are made that define trajectories of study and intervention.
\end{abstract}

KEYWORDS

Craft work. Crafts. Artisans. Capitalism. Creativity. 


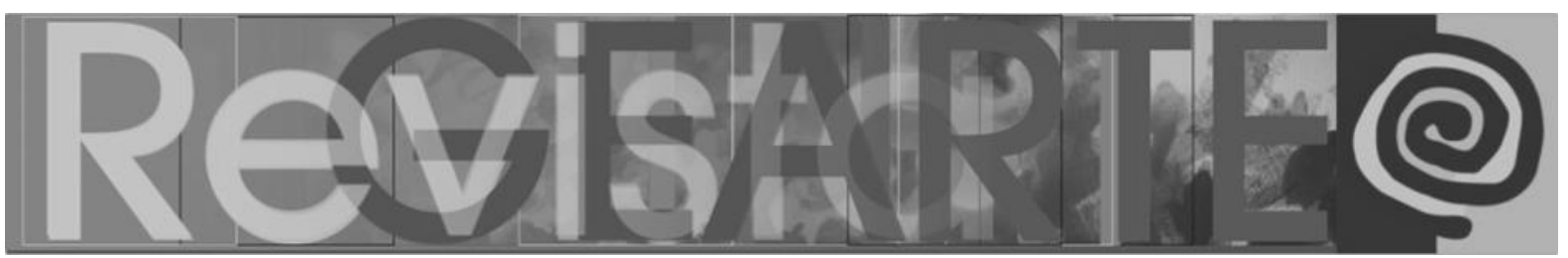

\section{Introducción}

¿Cuál es la compresión contemporánea de la artesanía o de lo artesanal?, ¿cuándo se habla de artesanal se podría hablar de un campo constituido o acaso puede pensarse como una práctica cultural natural de los seres humanos? y de forma actual, ¿qué relación tiene con las actividades creativas y/o artísticas? Estos cuestionamientos trazan trayectorias sobre la comprensión de la actividad artesanal y de la artesanía como una cuestión que requiere de análisis no solamente técnico sino también sociocultural, pues de allí puede tenerse un juicio claro de las posibilidades de desarrollo e intervención política sobre dicho fenómeno social. Actualmente el desarrollo de trabajos académicos sobre la actividad artesanal ha tenido un fuerte aumento en relación a diferentes condiciones, si trazáramos grosso modo la tendencia en las publicaciones sobre la artesanía (Figura 1), podría evaluarse un crecimiento tanto por la actividad propiamente dicha, como por la palabra como uso descriptivo y hasta metafórico. Así, esto expresa una consolidación de intereses políticos culturales que van desde las condiciones propiamente técnicas, empresariales, culturales, arqueológicas, artísticas, entre otras.

Figura 1 - Producción de textos sobre "artesanía" por año, tomado de la base de datos Google Académico en el periodo 1988 a 2018

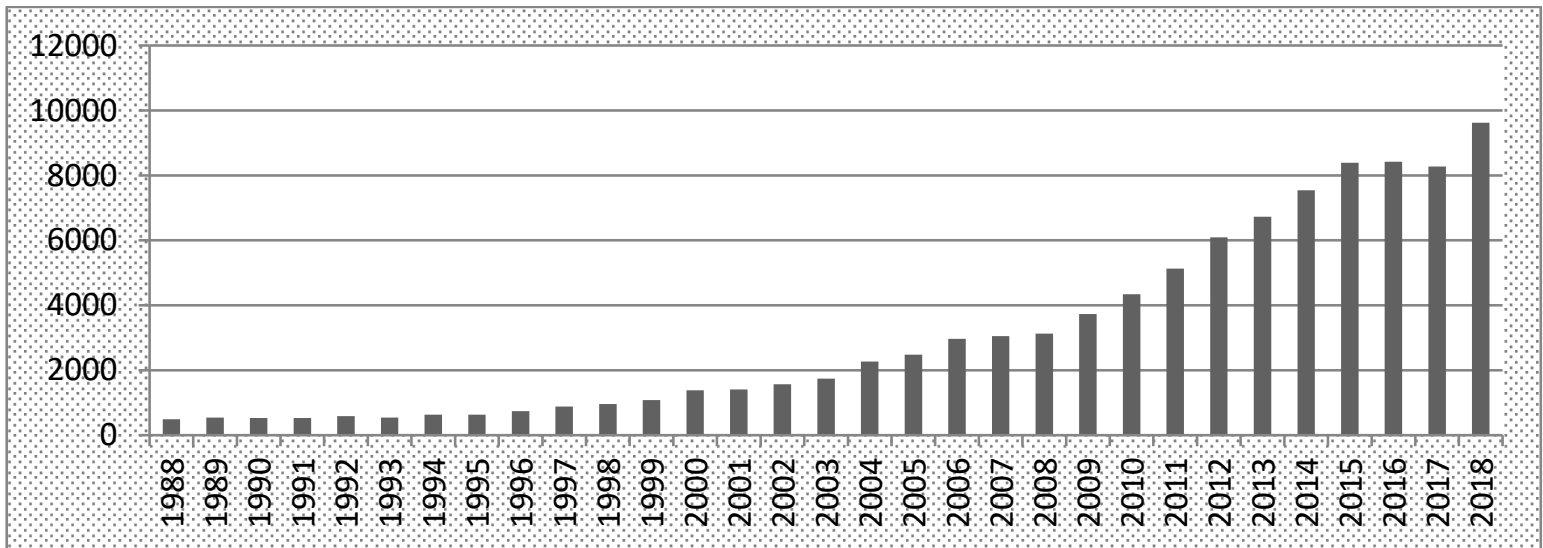

Fuente: Google Académico, Elaboración propia. (2019).

De esta manera, el peso de la producción confirma el desarrollo de un área de interés académico que puede indicar de forma directa o indirecta el

VEGA TORRES, Daniel Roberto. Trabajo artesanal, artesanía e industrias creativas: reflexiones en torno a las 462 transformaciones de la actividad sociocultural.

Revista GEARTE, Porto Alegre, v. 7, n. 3, p. 461-484, set./dez. 2020

Disponível em: http://seer.ufrgs.br/gearte 


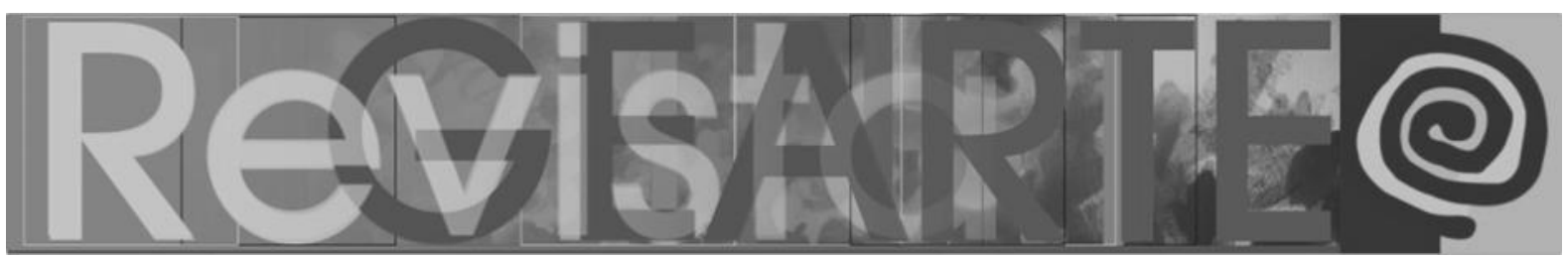

reconocimiento que la artesanía ha tenido como estudio en Iberoamérica. La complejidad de dicho proceso no deja de ser problemático si pensamos que la artesanía como estudio se compone de diferentes aristas que se pueden extrapolar a diferentes áreas del conocimiento, o que pueden considerarse divergentes entre sí, sin observar una base común de organización que cobije las diferentes expresiones del trabajo artesanal o de artesanía. En este sentido, tratar de responder la cuestión sobre la comprensión contemporánea de la artesanía puede que tenga que ir más allá de la apariencia naturalizada del objeto de estudio, y por el contrario definir una crítica sobre su conformación sociocultural que corresponda a sus posibilidades concretas.

En ese sentido, este estudio parte de una reflexión sobre lo artesanal como eje de problematización de la actividad humana, que corresponda con la historia concreta del desarrollo de producción dominante capitalista, tomando como hipótesis de estudio que solo mediante la comprensión del trabajo en un modo dominante de producción histórica se puede definir las condiciones de desarrollo y las transformaciones sobre las cuales se puede ejercer una comprensión pertinente para su correspondiente intervención y dirección. En ese sentido, la reflexión sobre lo artesanal no debe partir de un concepto "ideal", como usualmente se realiza a la hora de definir las características de dicha actividad, y donde los debates sobre los límites de lo que debe ser o no debe ser lo artesanal extrapolan la coherencia del estudio científico, derivando de esta manera en una imposición normativa del ejercicio administrativo. Por el contrario, pensar lo artesanal debe fundamentarse en las formas de desarrollo de las condiciones productivas generales de la sociedad.

De esta manera, mediante el desarrollo de la producción capitalista se podrá obtener un mecanismo de comprensión claro del fenómeno social. Así, se dispondrán de tres ejes de desarrollo e institucionalización de la actividad artesanal para la exposición: el primero desde una comprensión propia de la relación trabajo industrial y trabajo artesanal que permite la disyuntiva productiva y el 


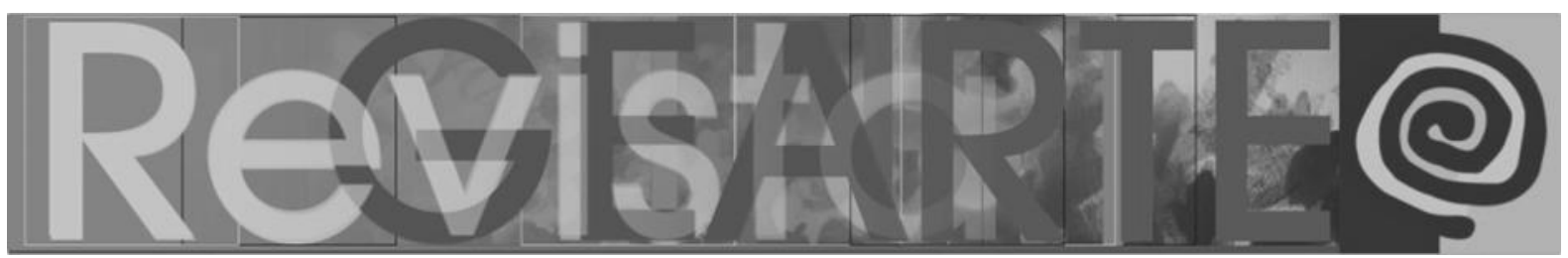

reconocimiento de identidades laborales y políticas. Un segundo momento del desarrollo de la industria cultural y la artesanía, como eje de la producción patrimonial cultural que permite un proceso de subsunción indirecta del saber hacer local a la acumulación capitalista; luego, la relación entre las industrias creativas y la actividad artística-artesanal, como parte de la subordinación directa del trabajo artesanal al capital, entendiendo su desarrollo en el mercado mundial. Por último, se presentará una relación de categorías que pueden ser utilizadas para el estudio e intervención de lo artesanal.

\section{Industria y Trabajo artesanal}

Uno de los aspectos principales trabajados en la historia de la formación del capitalismo industrial en el siglo XIX ha permitido profundizar en los cambios sociales de la producción, de donde puede permitirse evaluar cambios significativos entre lo que era propiamente pre-industrial como aquello que constituiría el desarrollo de una sociedad industrial. Ese periodo de división de la sociedad moderna sobre sus bases materiales de producción permitió que tanto el desarrollo de la cooperación de trabajadores, la construcción de las grandes fábricas y la maquinaria como eje de la producción permitiera un cambio en la consideración de la evaluación de la producción manual con herramientas simples, que estaba considerada como parte de los oficios de las ciudades en los diferentes territorios de la sociedad occidental. Tanto en la historia de los imperios como en la transformación de sus colonias, este cambio produjo una fuerte reacción en la organización de los trabajadores de oficios y gremios artesanales, que vieron vulnerados su forma de organización social y política, pues la dependencia de los gremios de artesanos a la vida cotidiana de las poblaciones tanto de las grandes urbes como de los pueblos de las colonias terminarían por evidenciar de manera violenta la proletarización de la población trabajadora.

Este cambio de las condiciones generales de la producción condujo a la formación de la clase proletaria de una manera mucho más rápida en Inglaterra, 


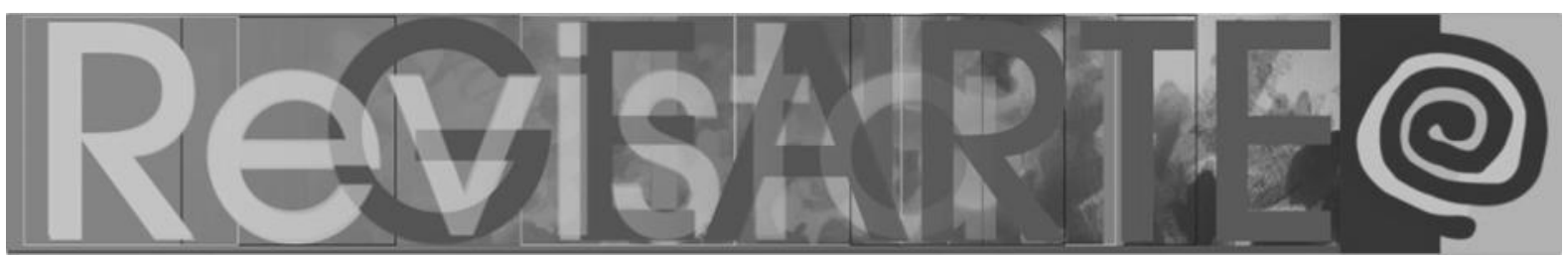

pero también se produjo un cambio en las condiciones de los pequeños propietarios de la clase media, que reaccionaban de forma organizada a una política de protección de los oficios artesanales en gremios con fuerte influencia en la organización política local y nacional, como aconteció en los territorios de la actual Alemania y Francia. En ese sentido, la actividad gremial de artesanos pudo verse contrarrestada por mecanismos sociales de lucha revolucionaria y contrarrevolucionaria de los gremios de artesanos (ENGELS, 1980). Para el caso, la proletarización de la población rural en migración a las ciudades y el dominio de la clase burguesa en la consolidación de un modo de producción capitalista dominante definieron la identidad de los artesanos.

La identificación de los artesanos como clase media corresponde a un proceso de organización política en las transformaciones materiales de producción industrial dominante, esto ocurre tanto en las sociedades de temprana industrialización, como en las colonias y excolonias. La experiencia de la organización laboral de los gremios artesanales en las colonias ya había tenido una reacción temprana en la liberalización de políticas comerciales que afectaban los oficios locales, quienes habían apoyado movilizaciones iniciales frente a las políticas imperiales de comercio y producción (LOAIZA, 2011). En un medio de producción local la diferenciación por oficios es más común para la identificación de los trabajadores, en ese sentido, la importancia del reconocimiento de los gremios no se presentaba como una identidad general de "artesanos", sino que se identificaban por oficios, zapateros, joyeros, pintores, escultores, etc (MORA DE JARAMILLO, 1974). En ese sentido, la diferenciación y distinción dentro de los gremios tenía que ver más con el material de trabajo y con la habilidad técnica que permitía un consumo de producción suntuosa, frente a labores de trabajo manual con materiales rústicos que representaban la vida pre-moderna.

Solo mediante la irrupción de la industrialización y la grande fábrica puede entenderse que exista una necesidad de identificación de los pequeños propietarios y trabajadores manuales que permitieran identificar su posición política 


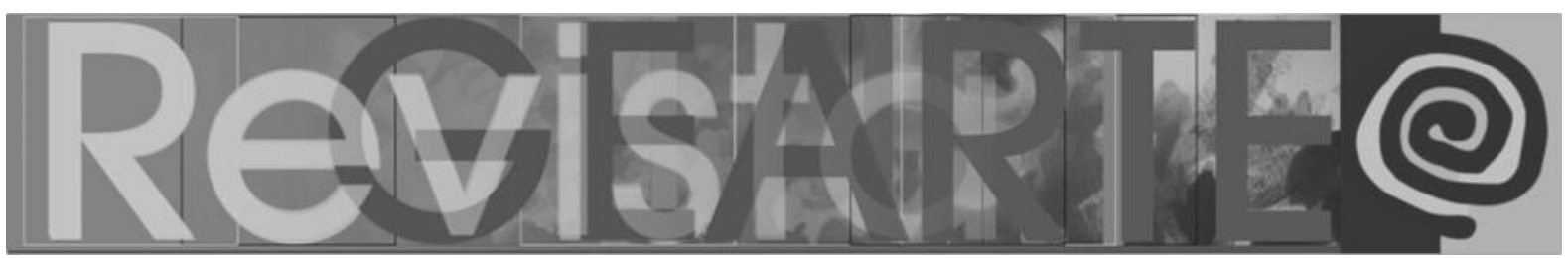

frente a los cambios económicos de producción y consumo en la sociedad. En Latinoamérica se encuentra este proceso político de sociabilidad de los artesanos desde una identificación positiva como clase social frente a los comerciantes, lo que deriva en una lucha indirecta de la transformación de la producción industrial en Europa, y que en este caso genera un movimiento internacional en la región que lleva a consolidar sociabilidades políticas de artesanos (LOAIZA, 2011). Cuando se consolida el proceso de identificación de lo artesanal en el capitalismo industrial decimonónico se produce un cambio más que técnico propiamente político, en donde los artesanos, en el sentido de hombres que socialmente pueden organizarse por sus oficios reconocidos social y culturalmente pueden integrar una clase social en el contexto histórico de dominio del trabajo productivo masculino.

Son los artesanos organizados en valores tradicionales de producción, pero no solo de valores técnicos sino también culturales, se aferran a producir discursos reaccionarios en su mayoría tanto a la clase burguesa de empresarios en creciente dominio del mercado, como de los trabajadores proletarios que no constituían una clase que tuviese las capacidades simbólicas que los oficios y la propiedad de los productores artesanales tenían en su haber, esos recursos de distinción familiar, religiosa, ociosa y cultural que frecuentemente constituía un escenario más cercano de identificación a las condiciones de la pequeña burguesía. Este notable ejercicio de desdoblamiento de la clase media que comentaba Marx (1980), fue parte del desarrollo general en cada uno de los países, pues solo en algunos casos de fuerte poder político como en Francia, Italia y Alemania pudieron permanecer los artesanos agremiados en su mercado interno (ZARCA, 1993), lo que actualmente da su valor diferencial en organización frente a otros sistemas de organización laboral de los artesanos. Pero esta situación no corresponde con las colonias y excolonias que debieron supeditarse a la integración del mercado de producción industrializada en la dependencia de mercados.

Con la llegada del siglo XX, la consolidación del capitalismo industrial y su proceso imperialista definió la transformación de las condiciones laborales en los 


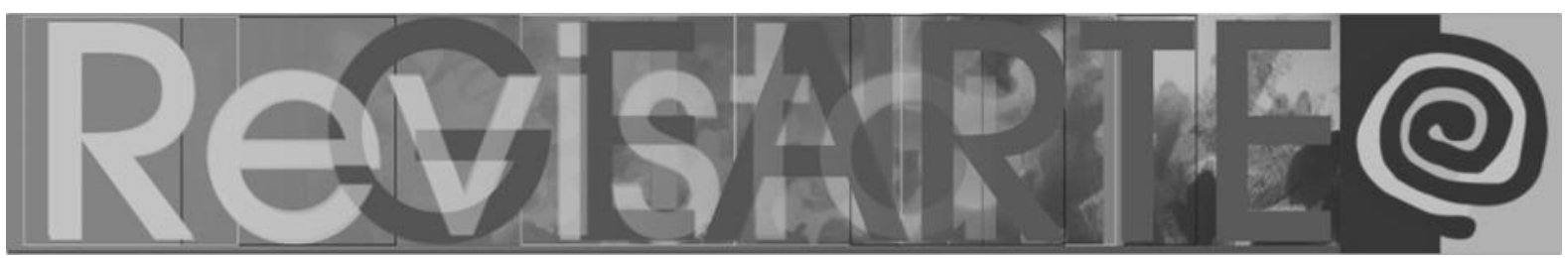

diferentes países tanto centrales como periféricos a la acumulación del capital. La situación de los artesanos en su lucha política pierde vigencia frente al crecimiento de las ciudades y los cambios en la forma de consumo e integración laboral mediante la formación de la clase obrera industrial que corresponde a un aspecto general de transformación de la vida familiar y cultural urbanizada. Lo artesanal como forma de producción se mantiene poco a poco en lo local, en la formación de lo rural como forma de vida contrapuesta a la modernidad que se vive en las ciudades. El trabajador autónomo en su oficio, propietario de su saber y de sus herramientas corresponde cada vez más a lo tradicional, a lo pre-moderno, y su identidad como artesano ya no va a competir con el sistema de reconocimiento y producción capitalista por su baja productividad, sino al sistema de reconocimiento de lo cultural, como símbolo del saber y el hacer.

\section{La industria cultural y la Artesanía}

Cabe anotar que cuando se habla de forma dominante de producción capitalista no tiene que corresponder a que exista únicamente una producción industrial con una proletarización general de la población trabajadora, sino que por el contrario, es el poder que ejerce la transformación de una forma de producir lo que termina afectando directa o indirectamente la organización social del trabajo de manera amplia. En este sentido, aunque en el siglo XX comienza el crecimiento de las ciudades y la forma de vida moderna corresponde con un consumo de mercancías industrializadas en un mercado mundial, es necesario identificar que el desarrollo capitalista también permitió la constitución de un proceso diferencial de la vida comunitaria local o rural. Si no se integraba la población a la vida urbana, es posible que la manera de vivir, pensar y producir tuviese que definirse de manera contrapuesta, pero en muchos casos dependiente del sistema dominante.

Este proceso de identificación de la producción artesanal tiene que ver más con un proceso de comprensión y estudio de lo cultural como eje del reconocimiento, es decir, en un primer momento los estudios sobre las poblaciones 


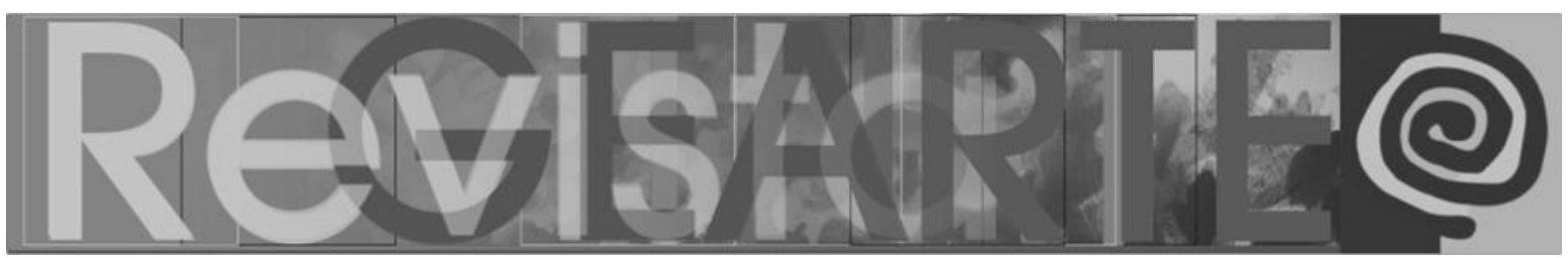

rurales, derivadas de la etnografía, la antropología y la sociología definieron características de la población en los discursos que definían formas de producir y vivir. Es así que en este mecanismo de caracterización de la población se ejerce un reconocimiento externo, de los académicos hacía la población, que terminan por definir la actividad social local pre-moderna como una actividad cultural o folclórica, es decir que hace parte del estudio eurocéntrico colonial de la mirada de la producción y forma de vida que encajaba en la comprensión de la "naturaleza" de dichas poblaciones, especialmente de indios, negros y asiáticos.

La formación de la artesanía como estudio corresponde a un ejercicio de poder de definición de las formas de vida y las formas de producción rural, preindustrial y pre-moderna que fueron clasificados desde la noción colonizadora de la diversidad en las formas de producción local, dependientes de los territorios tanto por sus condiciones físicas (recursos materiales, recursos ambientales) como de sus condiciones sociales (cultura, memoria, tradición, aprendizaje). En ese sentido, el objetivo del conocimiento no se encontraba en los sujetos propiamente tales, sino en los objetos, en la "artesanía", es el objeto la razón de estudio, saber y clasificación, una clasificación que ponía de manifiesto el folclor y la cultural de lo local en un ejercicio homogéneo de identificación a lo largo de los territorios colonizados o periféricos a la vida moderna.

Mediante la "racialización" de las poblaciones periféricas (CAMPOS, 2012), rurales o minoritarias, adquieren un valor naturalizado que exige del discurso académico crear la correspondencia entre el ser social como ser natural, en esto consiste la clave de los discursos sobre la producción de artesanías a lo largo del siglo XX, pues se concentra como un debate sobre la aprehensión de lo distinto a la vida occidental, urbana e industrial. De esta manera se reproduce ideológicamente el mito de la artesanía como parte de la naturaleza humana. La artesanía no solo encubre un estudio etnográfico y colonizador de la nomodernidad, de la otredad, sino que además fortalece esa distinción en la descripción del objeto sobre el sujeto, pues en este caso no se puede ser artesano 


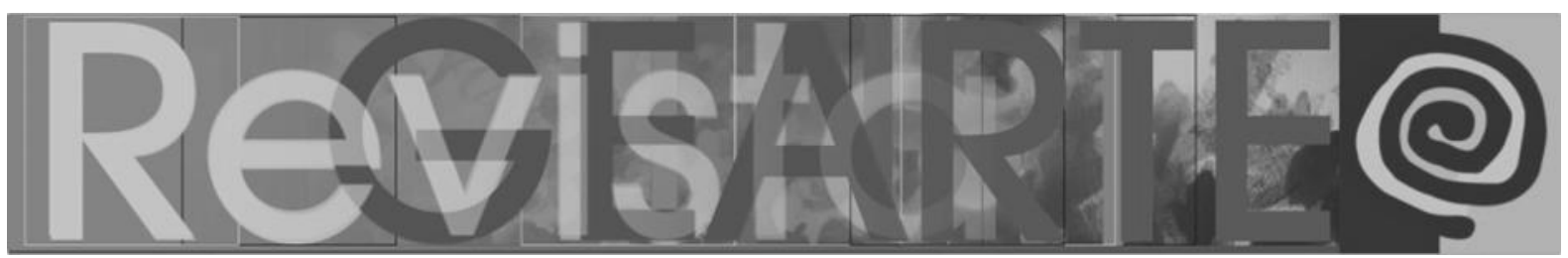

sin antes presentar de forma clara cuál es la artesanía que produce. Este juego de dependencia del artesano y la artesanía en donde se institucionaliza la actividad artesanal puede ser el paso clave de su desarrollo como objeto de estudio cultural.

La genealogía del término artesanía, que puede ser más extenso en su desarrollo práctico y científico (MEJÍA, 2004), pero corresponde en este caso a un uso específico de identificación cultural de las poblaciones rurales o periféricas. Periféricas en la producción, porque los medios continúan siendo la fuerza física o la herramienta simple, a diferencia del desarrollo técnico y tecnológico industrial. Periféricas en la sociedad, pues son las poblaciones no occidentales o premodernas las que constituyen el objeto de análisis y clasificación. Periféricas en los recursos, pues se trabaja sobre materiales como la madera, el carbón, el barro, el algodón, o las fibras naturales en general, frente a los metales y polímeros industrializados en la gran industria. Periféricas en la división sexual del trabajo, pues las mujeres van a tener una mayor participación en dicha producción, las actividades domésticas de reproducción social de la vida comunitaria van a integrar una forma de vida cultural y étnica definida en la producción de artesanía.

Las mujeres van a sostener el proceso de organización del trabajo artesanal, pues son principalmente ellas las que van a producir un proceso de identificación y organización comunitaria como artesanas, artesanas que producen artesanías (VEGA, 2013), y es allí donde las unidades productivas que en el silo XIX tenían locales en las zonas urbanas, van a trasladarse a los hogares de las familias rurales donde la división sexual del trabajo, entre las labores de agricultura se entrelazan en obligaciones dominantes sobre la producción doméstica de las mujeres en su saber hacer propiamente dado para los útiles domésticos. En ese sentido, el mobiliario y utensilios domésticos que fueron organizando los mercados en los centros urbanos y en las plazas de las ciudades mediante la migración interna de la población rural, va a ser el paisaje principal de reconocimiento de la actividad artesanal a lo largo del siglo XX. Que se haya identificado la artesanía 


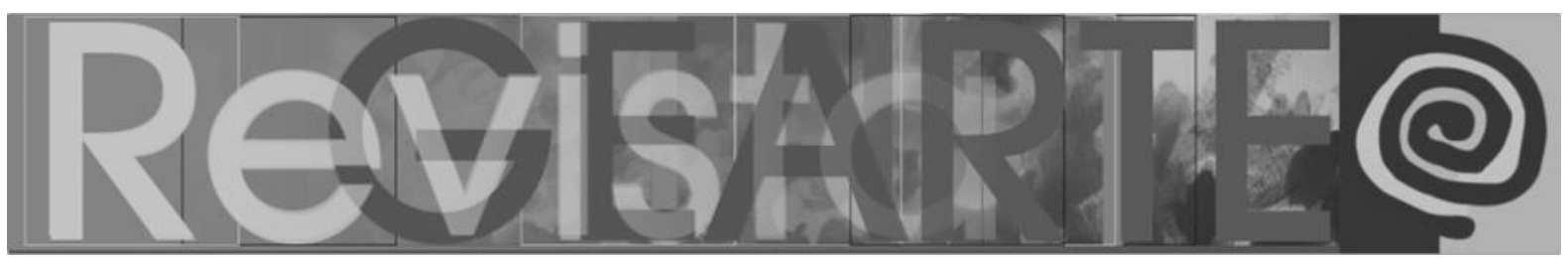

con la producción doméstica femenina es un ejercicio de naturalización de la dominación masculina de la reproducción de la vida social.

Sin embargo, este proceso que inicia en la primera mitad del siglo $X X$ como un mecanismo de reconocimiento, naturalización y clasificación, tiene su continuidad en el proceso de integración a la producción capitalista en la medida que se subordina este tipo de producción y se territorializa el mercado local como parte de la actividad del consumo turístico y cultural de la clase media y la clase trabajadora urbana. Parte del desarrollo de la industria cultural de la artesanía se integra indirectamente mediante el consumo en la sociedad capitalista y no en la transformación de los medios de producción. Este ejercicio de integración es lo que Néstor García Canclini consideraba como la "hibridación" de la cultura, lo que en sus bases materiales consistía en lo que Marx llamaba como la subordinación indirecta de la producción al capital. Este mecanismo de dominación de la cultura no corresponde directamente a una racionalidad instrumental de los productores, como mencionaba Adorno y Horkheimer, sino que es en el desarrollo desigual y combinado del capital en el mercado mundial donde se identifican las formas no occidentales de vida en comunidad, que terminan por ser parte del circuito total de acumulación y concentración del capital.

Así, el modo de desarrollo fordista de la gran industria que constituye la forma de organización política, económica y social del trabajo a lo largo del siglo $\mathrm{XX}$, presenta una integración indirecta de las formas dominadas de producción cultural rural mediante la posibilidad de consumo de la clase trabajadora o de los obreros urbanos. Sin este proceso de consumo, la producción artesanal como mercado local no tendría como reproducirse, lo que podría haber llevado a permanecer a la población de las comunidades rurales en una producción de subsistencia. Es precisamente ese paso de la producción de subsistencia a la producción de un mercado local dependiente de la sociedad capitalista industrial lo que define el espacio social donde se estructura el campo social de la actividad artesanal en el siglo XX. 


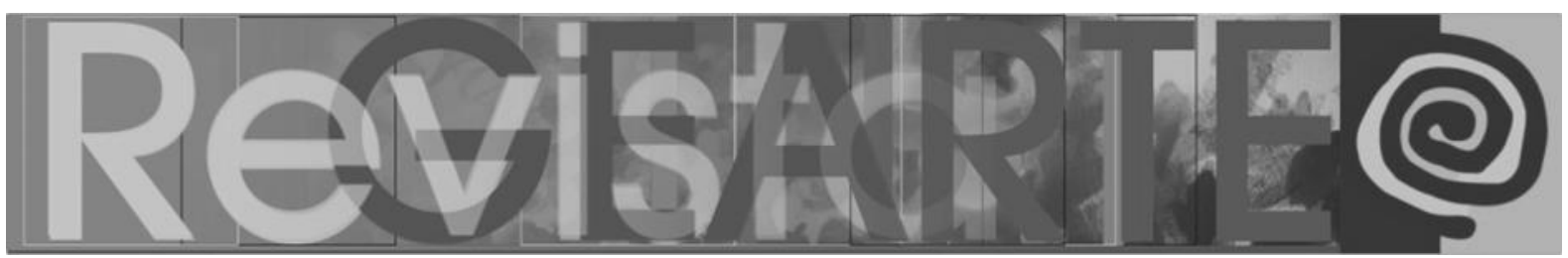

Más reconocido el término, y más socializado desde la academia, es posible que la artesanía haya tenido ese crecimiento en los estudios que aparece en la figura 1, como mecanismo de reconocimiento y relación entre lo rural y lo urbano, tanto desde un proceso de intervención económica para el mejoramiento de las condiciones productivas de las artesanas, integradas en su contexto rural y su aplicación en la organización del mercado en la comercialización hacia las ciudades; como desde la crítica socioeconómica de la producción desde las desigualdades, la pobreza y la marginalidad en donde se desarrolla la actividad artesanal, especialmente en los países del denominado "tercer mundo". Allí la formación cultural de las poblaciones como mecanismo etnológico de reconocimiento y auto-reconocimiento van a permitir que las formas de lucha de las comunidades tomen como recurso los símbolos, tradiciones y expresiones locales frente a la globalización.

La institucionalización de la artesanía se constituye como un correlato al desarrollo capitalista, colonialista y patriarcal que constituye el fordismo. El Estado como forma de promoción y protección de las políticas públicas termina validando en un principio las condiciones folclóricas de la vida en lo local al ser patrimonio cultural, tanto como por incentivar procesos de reconocimiento formal de las actividades, empezando por la formación de leyes correspondientes a la planificación de la actividad en cada país. Este proceso que se consolida en la segunda mitad del siglo XX permite tanto naturalizar la actividad de la artesanía, como delimitar la participación de las categorías de artesanos en la población. Proceso que debido a la informalidad de la actividad, inscrita en la cotidianidad del trabajo flexible pago y no pago de las mujeres, sufrió siempre problemas en la consolidación de la identificación de las trabajadoras. No obstante, como ley, se ha consolidado en los países la necesidad de reglamentar la actividad, siendo la conceptualización el principal problema para la definición de quién es artesano y qué es artesanía. 


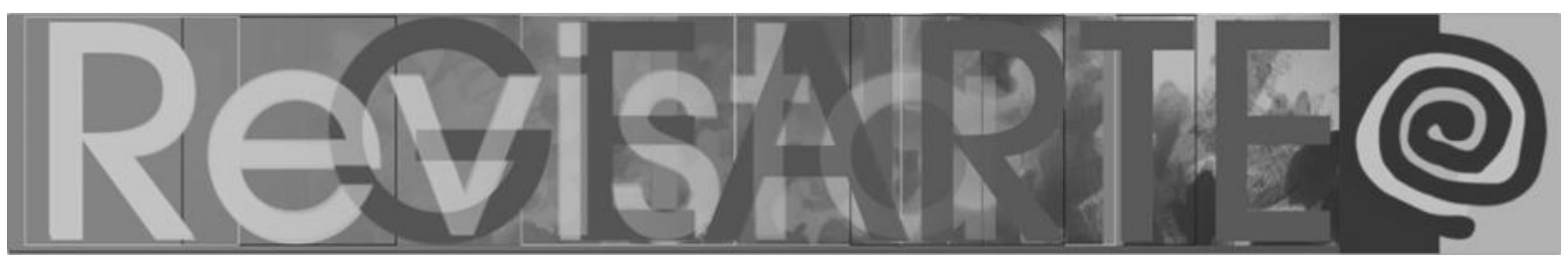

Por otro lado, la identificación de las artesanas en las zonas rurales presenta problemas comunes de acceso y apropiación de los recursos que les permitan mayor justicia en el mercado. La estabilidad económica, la competencia con comerciantes, los bajos precios de venta y la baja calificación técnica, entre otras, son una constante en la población artesana de objetos utilitarios, folclóricos y culturales. Esta manera limita la identidad de la población trabajadora, o que depende del trabajo a fragmentarse en asociaciones locales y regionales, pero que por la misma reproducción del objeto de su actividad cultural no consiguen superar su dependencia a la clase trabajadora formal de ingresos medio y alto. Puesto que además de luchar por la producción industrializada de baja calidad y de menor precio, de productores de otros países y regiones, deben competir por la diferenciación de productos entre los mismos productores para que exista una estabilidad financiera.

Pese a estas situaciones, las propuestas de alternativas al desarrollo capitalista utilizan las representaciones de la artesanía como parte de la contraglobalización, en donde lo valores comunitarios y de cuidado son exaltados en las poblaciones marginadas y excluidas de la acumulación y concentración capitalista. La economía social y solidaria adhiere en sus principios una forma de producción que considere el trabajo artesanal como respuesta hacia el daño ecológico social provocado por la producción dominante capitalista (KELLER, 2011), y que contribuye a crear símbolos locales de resistencia mediante prácticas que consideran valores propios y valores de uso como el eje principal de la transformación productiva hacía otra sociedad. Sin embargo, este proceso basado en la artesanía puede tener problemas prácticos en la crítica al sistema capitalista, cuando la misma actividad artesanal puede encubrir valores excluyentes, discriminatorios y políticamente fragmentados. 


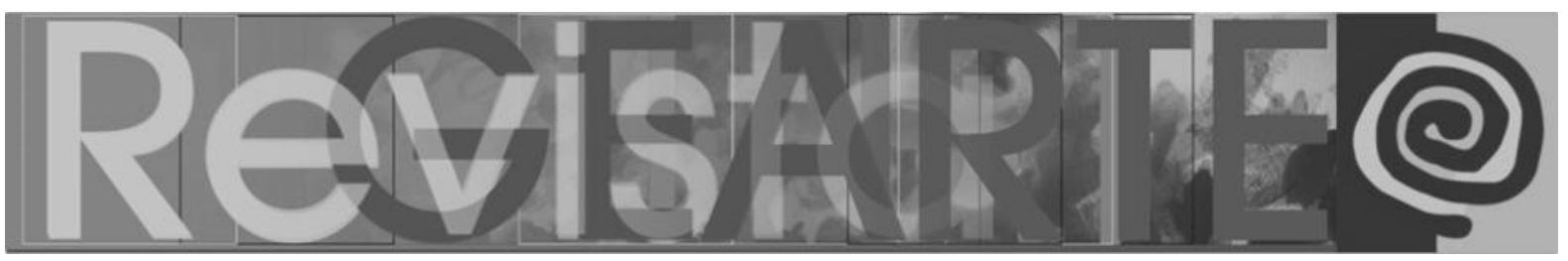

\section{Industrias creativas y actividad artística}

Si por un lado el fordismo representaba el modo de desarrollo de la sociedad industrial, por otro lado la crisis de los setenta y la reestructuración productiva que trajo consigo disminuyó la concentración de trabajadores en la grande industria, y por el contrario, existió un crecimiento del sector servicios, donde actividades de tipo administrativo y de gestión permitieron modificar la forma en que se organizaba el trabajo, lo que de manera correspondiente trajo consigo cambios en la manera como se observaba la producción artesanal. El pós-fordismo, como expresión de los cambios productivos en que se fundamentaba el capital, principalmente de un proceso de acumulación del capitalismo industrial a una sociedad de dominio del capital financiero permitía la descentralización y desterritorialización de la producción en los países industrializados (CUNNINGHAM, 2002), obteniendo mayor ganancia en la explotación laboral en diferentes países subdesarrollados.

Esto trajo consigo que la disminución de un trabajo formal en la sociedad industrial, y un crecimiento en la población laboral informal que tenía consigo el peso de una transformación productiva sin acceso directo a sus beneficios productivos. Con el desarrollo de políticas neoliberales desde los años setenta y ochenta, se concibe un mecanismo de individualización de la clase obrera, fragmentando las condiciones de reconocimiento en la promoción de competencia para el mercado, creando un discurso de éxito para los mejores, como esfuerzo voluntarista del empresario. Cada uno sería un empresario de sí, pues el recurso principal de explotación que es el trabajo sería ofertado como capital, capital humano, para obtener beneficios productivos en el mercado. El micro empresario transforma al pequeño propietario de la clase media tradicional en un emprendedor capitalista a pequeña escala.

La artesanía como actividad cultural no corresponderá a esa protección como patrimonio de lo local desde el Estado, sino que por el contrario, en un proyecto neoliberal, tendrá que afrontar las transformaciones productivas desde la 


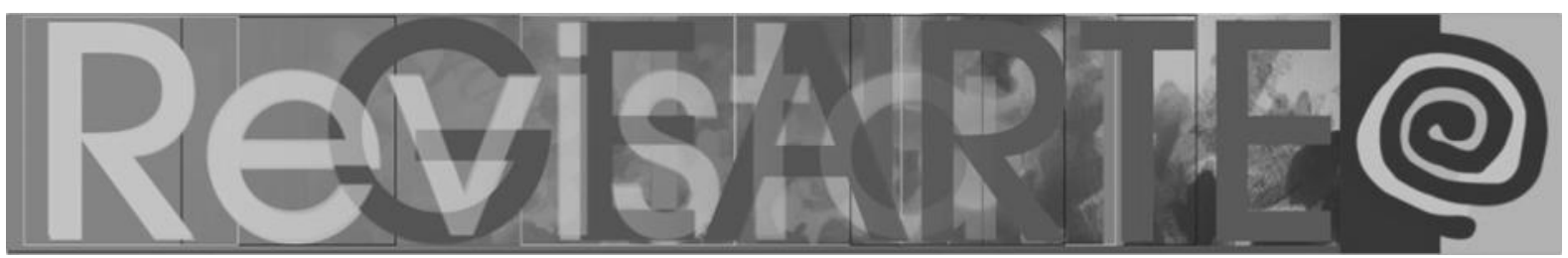

producción propiamente dicha, ya no podría dependerse del consumo de objetos tradicionales y folclóricos, sino que debería llevarse a cabo un desarrollo específico técnico y tecnológico de la producción que ofreciera un mejoramiento en los productos para competir de manera más rentable en el mercado. En este sentido aparece el diseño, y el diseño artesanal, como eje principal de configuración de un nuevo proceso de la actividad artesanal. Sin el desarrollo del diseño industrial aplicado a la producción artesanal no podría comprenderse la situación actual de la artesanía, pues es en la intervención de profesionales técnicos calificados como poco a poco se desarrolla un mercado de artesanías cada vez más especializado (QUIÑONES; BARRERA, 2006), donde la correspondencia entre las pequeñas empresas y emprendimientos urbanos y rurales van a obtener mayor representatividad en el mercado nacional e internacional.

Así, la participación de profesionales del diseño y del arte van a crear trayectorias de mercado de productos cada vez más diferenciados para una proyección de lujo y arte (AVELINO, 2007), donde las correspondencias entre los productos ya no van a desarrollarse hacía lo tradicional, hacia la memoria como un recurso patrimonial que debe protegerse y mantenerse, en esa ilusión mítica y estática de la artesanía que tanto impacto a principios del siglo XX, sino que debía individualizarse la producción, enseñar a producir con técnicas y valores estéticos y artísticos cada vez más autónomos, donde el artesano no se debía a su oficio a la manera tradicional, sino que los artesanos deberían producir distinciones como marca, es decir su nombre, su local, o su unidad productiva como signo distintivo que corresponde a la técnica, a la obra y al productor artesano-artista, en un régimen de identificación y representación que puede llegar a validarse en la legitimidad del campo artístico.

En este espacio de transición del fordismo al pós-fordismo, las mujeres, los jóvenes y los adultos mayores como población excluida directamente del mercado laboral formal, atienden a la participación de sus actividades auxiliares en microemprendimientos de artesanía, como trabajadoras autónomas que pueden llegar 


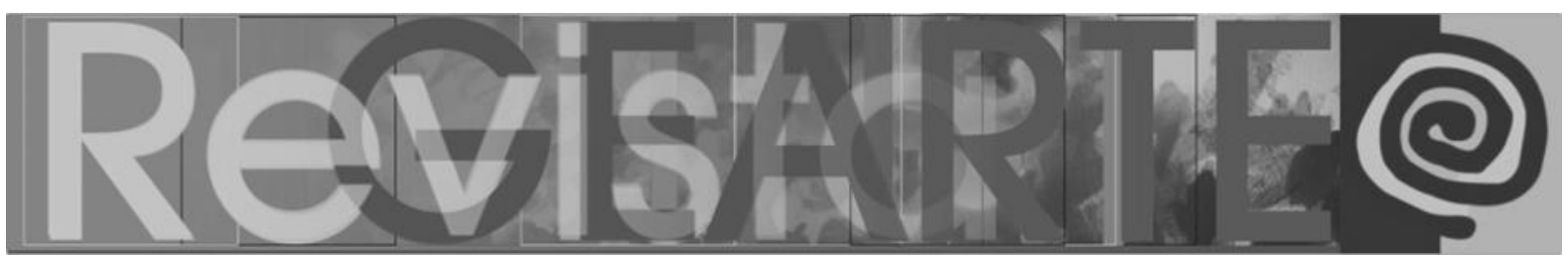

a trasladarse en ocupaciones transitorias entre la profesión, las artesanía o microempresa artesanal y el trabajo de cuidado (FIGUEIREDO, 2015). Estas manifestaciones promedian los ejemplos de la población que por algún motivo recurre a actividades de trabajo auxiliar o complementario, lo que incentiva un mercado de bienes de producción cada vez más especializado en las ciudades, que consiste en materia prima de industria nacionales e internacionales, lo que de alguna manera termina por subordinar directa y formalmente el trabajo de la artesanía al desarrollo capitalista. Por ello, el crecimiento de la producción académica en el área de administración y diseño ha sido constante conforme se requiere intervenir en el trabajo artesanal para una mayor productividad.

De manera correspondiente, si el modo de desarrollo fordista que considera condiciones de producción de la gran industria, en donde las industrias culturales eran subordinadas por mecanismos de una sociedad de consumo en las condiciones que el capitalismo industrial dominante permitía en la estructuración de un mercado nacional. El correlato del proceso pós-fordista de la reestructuración productiva va a ser la clasificación y organización de las industrias creativas, pues no va a ser lo "cultural", entendido esto como valores simbólicos destinados al mercado de masas, sino la creatividad, entendida como el valor del productor en sí que se ofrece al mercado desde sus habilidades y condiciones simbólicas y corporales, lo que termina por dar acento al proceso de transformación neoliberal que va más allá de la simple reflexión de la palabra cultural y de la palabra creatividad. En este sentido, el paso de las industrias culturales a las industrias creativas como modo de desarrollo no es una etiqueta y sí un mecanismo de dominación de la producción y del productor en sí.

Las industrias creativas que se estructuran como política de organización laboral en Inglaterra en los años noventa, y que toman fuerza en los países desarrollados en la primera década del siglo XXI (UNDP, 2013), hasta convertirse en política de clasificación mundial de la producción cultural, consideran el trabajo artesanal como parte de ese gran conglomerado de actividades creativas que 


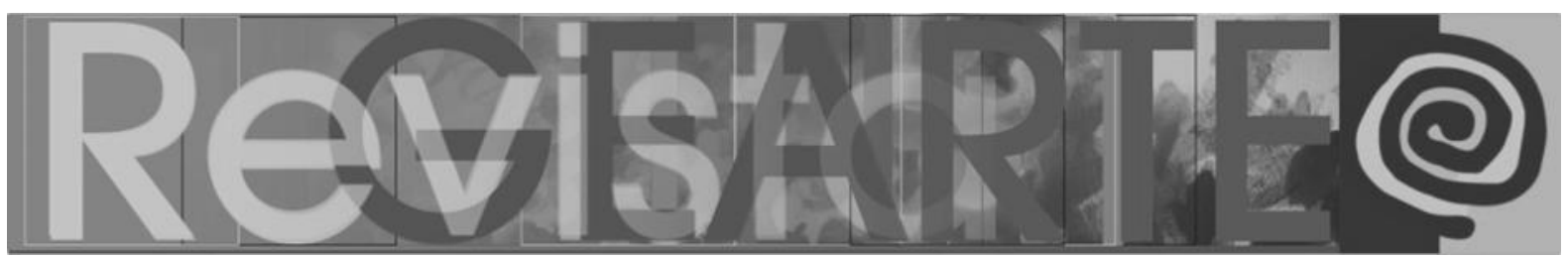

permiten evaluar un desarrollo de las habilidades de productores artísticos y culturales, que van desde las actividades de mayor desarrollo tecnológico y científico, como la producción cinematográfica y el desarrollo de tecnologías 4.0 como aplicaciones y formatos virtuales de comunicación, exposición y comercialización, hasta actividades de carácter más técnico como la artesanía, con avances de diseño en aplicación de materiales y transformación productiva material. Este gran abanico de actividades laborales que constituyen las industrias creativas, da paso a un debate sobre el trabajo creativo dentro del proceso neoliberal de la globalización.

El desarrollo de actividades culturales y creativas constituyen un objeto de estudio contemporáneo, en donde se busca poner en contexto la producción cultural en función de aquellos artesanos artistas y diseñadores que transformen lo tradicional en un medio de desarrollo estético y artístico que participe de exposiciones y mercados especializados en el consumo de lujo (FREITAG, 2014). En ese sentido, existe un proceso de homogeneización global del trabajo artesanal que corresponde con una transformación empresarial y artística de trabajadores autónomos que participan de un mercado global de exposición y reconocimiento. Los Estados participan de la promoción de la actividad artesanal en la forma de desarrollo artístico y competitivo mediante concursos y premios a los mejores productores, pero que en relación a políticas de fondo para el total de la población de artesanas y artesanos ha sido más bien débil, por el costo de asumir constantemente una actividad que transita entre la informalidad, la marginalidad y el trabajo ocasional (SCRASE, 2010).

Por último, es posible identificar mecanismos de protección del trabajo artesanal en lo cultural desde un ejercicio de territorialización de la marca, es decir, mientras que en las zonas urbanas se obliga a los productores a obtener un reconocimiento individual como trabajadores autónomos mediantes las marcas o signos distintivos, en las zonas rurales donde la producción mantiene los saberes comunitarios se territorializa la marca con las indicaciones geográficas o las 


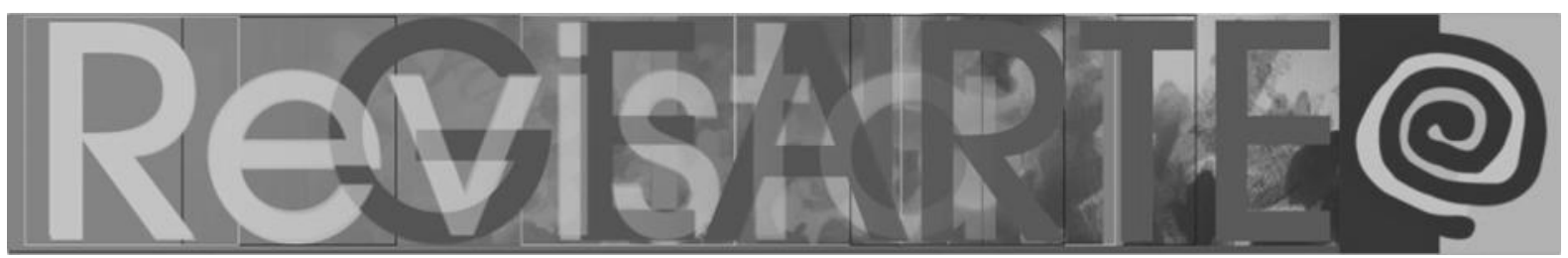

denominaciones de origen (JURADO; AGUILAR; JUAJIBIOY, 2014). En ese sentido la manera de proteger la actividad cultural es con la protección de derechos de producción desde los territorios, como formas de mantener una autonomía en la producción que salvaguarde la competencia en el mercado mundial. Sin embargo este tipo de desarrollo no escapa de la lógica de la acumulación del capital, puesto que la productividad no se mide propiamente en la transformación técnica y tecnológica de las unidades productivas, sino en la renta monopolista que busca ganancias indirectas en el valor agregado que obtienen los productos en el mercado internacional.

Así, tanto en la subordinación directa en la transformación técnica de los productos para un consumo de lujo, como de la subordinación indirecta en la territorialización de la producción mediante la renta monopolística, la actividad artesanal constituye hoy un escenario de debate entre una gran cantidad de personas que transitan entre las posibilidades de transformación en el mercado mundial, donde la precarización y la exclusión de los trabajos formales obliga a una participación cada vez menos valorizada en lo general, pues aún en el caso que exista un proceso de integración a la valorización estética como forma de legitimidad simbólica y material de las obras en el campo artístico, que se observa en el desarrollo cada vez más autónomo y de auto-reconocimiento de los artesanos como artistas, esto solo corresponde a un pequeño grupo de casos exitosos en la creciente población de trabajadores artesanales, artesanos y artesanas que aun trabajando en las condiciones desiguales de su local continúan con la actividad.

\section{Reflexiones sobre las categorías en lo artesanal}

Al tener en claro que solo desde las condiciones de la totalidad concreta del modo de producción capitalista se pueden observar las diferentes manifestaciones de lo artesanal, es posible llegar a algunas reflexiones sobre cómo crear categorías correspondientes a la actividad artesanal. Esto se realiza como crítica a las definiciones ligeras que se han realizado desde la conceptualización formal e ideal 


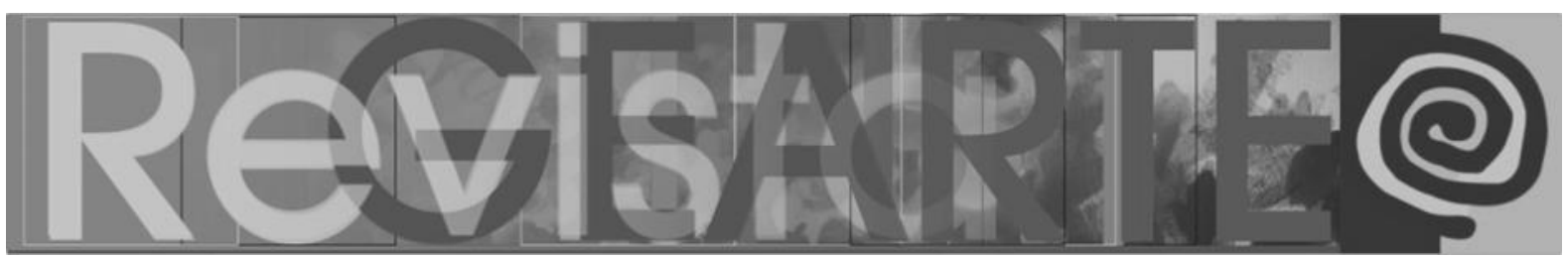

de lo que debería ser la actividad artesanal, empezando por la reflexión transhistórica de Richard Sennet (2008), que contempla a lo artesanal como un trabajo "bien hecho", esta vaguedad de la definición recuerda la crítica de Hobsbawm a Foucault quien decía de él que "rebuscaba en la historia para pescar ilustraciones al servicio de una narrativa preconstruida" (HOBSBAWM, 2016, p. 50 ), esto no implica que el ensayo sobre el artesano pierda importancia desde su filosofía pragmática en correspondencia a su "sistema" filosófico sobre el saber hacer, saber ser y saber-saber. Sin embargo, para él la artesanía solo sería un ejemplo más de ese hacer bien hecho, lo que elimina cualquier proceso real de comprensión e intervención política.

Por otro lado, también se hace una crítica a las reflexiones latinoamericanas que busca poner límites desde los conceptos formales de lo que es o no es artesanía. Aún comprendiendo la necesidad de implementación de políticas públicas de la actividad artesanal, este esfuerzo ha perdido el horizonte promoviendo debates inacabados sobre la mejor forma de conceptualizar la actividad artesanal, partiendo siempre de una serie de generalizaciones que no constituyen un horizonte confiable de clasificación, pues en su mayoría solo reproduce lugares comunes de la artesanía como cultura naturalizada de la población indígena, afroamericana o "contemporánea". La artesanía para estos documentos entonces es indígena, artesanía tradicional, artesanía contemporánea, neo-artesanía, industrianato, etc. Todas estas clasificaciones parten de esquemas conceptuales abstractos y ofrecen un resultado didáctico pero carente de crítica histórica.

Teniendo en cuenta esto, la propuesta de categorías parte de una reflexión del trabajo concreto que constituye el mecanismo de interpretación general de la actividad humana y que permite entender el proceso de subordinación frente a un sistema histórico dominante de producción material. Entender que solo mediante el desarrollo de una división el trabajo desde el modo dominante de producción se 


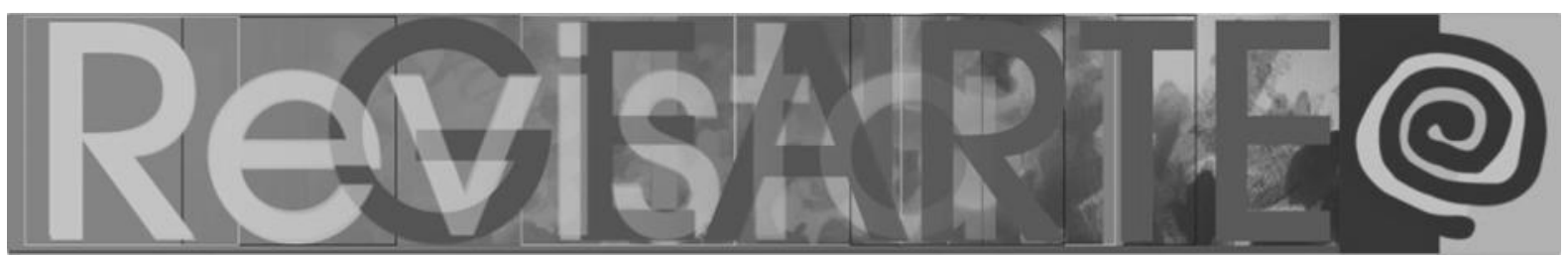

puede definir de manera más dinámica lo artesanal. A continuación se explica la actividad artesanal en relación a una división social, técnica y simbólica del trabajo.

El trabajo artesanal se entiende como una categoría histórica y geográfica que representa una dimensión de la división del trabajo en una sociedad específica, y que constituye un medio de reconocimiento técnico, simbólico y social de organización de la producción, que como tal define su condición diferencial en relación a los desarrollos técnicos y tecnológicos en otras áreas de producción industrial y de servicios. En ese sentido representa formas de trabajo de la producción técnica básica o primaria, dada principalmente por la determinación negativa que se deriva de los avances tecnológicos de una sociedad. Por ello, hablar de trabajo artesanal puede ser relativo al estado de la producción técnica y tecnológica en un periodo histórico, y no puede pensarse como una categoría natural del saber-hacer humano.

La actividad puede pensarse desde la división técnica del trabajo artesanal de una forma histórica de producción donde el trabajador y su producto comparten una serie de características técnicas simples o básicas, en donde se considera la habilidad individual y la herramienta -o maquinaria simple- como el apoyo principal en la producción, este tipo de organización depende del reconocimiento del oficio y de su tamaño, pues el ejercicio de la actividad debe mantener las proporciones ajustadas a un número que permita que el trabajador pueda encargarse de la mayor parte del proceso de producción. En esto consiste el reconocimiento de actividades destinadas a la construcción, los alimentos, o la fabricación de productos utilitarios a base de recursos naturales como el cuero, la madera, el metal, entre otros. Esta definición del trabajo artesanal tiene mayor relación con la clasificación del a Organización Internacional del Trabajo, en dónde se presenta la técnica, la habilidad y la profesionalización como indicadores de reconocimiento.

La división simbólica del trabajo artesanal constituye un proceso de reconocimiento cultural, en donde se encuentra en relación símbolos, textos, 


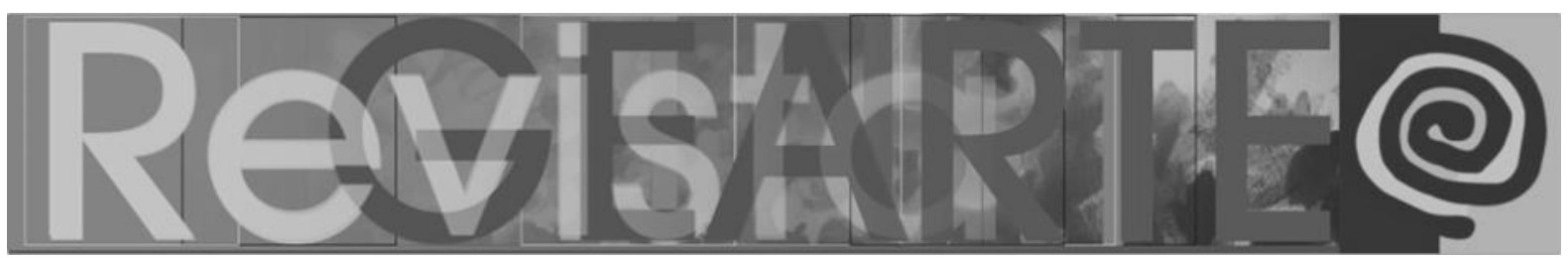

contextos y significados en la producción, allí aparece la división principal de subjetividades entre la artesanía y el artesano como agente cultural. La artesanía no constituye sólo la división técnica, que presupone el trabajo artesanal, sino que además debe estar constituido por una serie de contenidos institucionalizados en la memoria y las tradiciones que correspondan con la identificación de valores históricos y culturales, lo que define a cabalidad la importancia del objeto artesanal como producto de la cultura, como parte del patrimonio de un lugar o de una nación. Ser artesano o artesana depende de la producción de dicho objeto cultural, donde se construye la narración del valor mediante su legitimidad en el campo social que lo constituye. Por eso, el artesano no depende únicamente de la técnica. Así, un trabajador artesanal como el albañil no va a ser fácilmente reconocido como artesano a menos que constituya junto con él una artesanía que corresponda simbólicamente con la legitimidad del campo como marco de representación válido.

Por último, la división social del trabajo artesanal exige la diferenciación de las posiciones de clase entre los productores, en ese sentido no todos los artesanos, trabajadores artesanales 0 productores en general pueden corresponder a posiciones de clase homogéneas Para ello, los recursos de distinción sobre el modo de producción dominante dan claridad a los procesos de distinción de clase. Por un lado se presentan los pequeños propietarios, posicionados en la clase media tradicional de productores que se reconocen en la consolidación de micro y pequeños emprendimientos, y que pueden constituir tanto los empresarios de oficios artesanales a pequeña escala, como productores artesanales de la artesanía que compiten en mercados para el posicionamiento de la marca y de su producto.

Por otro lado se encuentran los trabajadores asalariados, que como trabajadores artesanales pueden depender de pequeñas empresas, siendo contratados en subordinación a los pequeños propietarios o empresarios, esto corresponde con la división de los trabajadores formalmente integrados a unidades productivas mediante la venta de su fuerza de trabajo (MAZAUD, 2009). Estos 


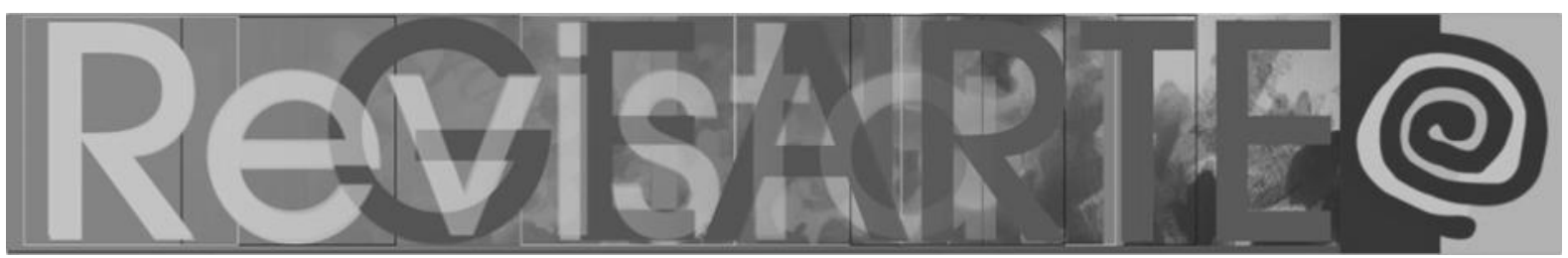

casos de asalariamiento dependen principalmente de unidades productivas urbanas, y donde la clase de pequeños propietarios es más fuerte y reconocida en el mercado nacional. Por último las trabajadoras y trabajadores por cuenta propia, como agentes de producción que no se reconocen dentro de la clase media, sino que son trabajadores que transitan desde la producción precarizada hasta la formalizada en las zonas rurales y periurbanas. En otras palabras, es la clase-quevive-del-trabajo y que corresponde con la población en situación más vulnerable para encontrar una continuidad y sostenibilidad en la producción artesanal.

Desde la división del trabajo sobre el desarrollo del capital, como forma dominante de producción, se puede obtener un ejercicio claro de las diferentes formas en que aparecen los trabajadores artesanales, en especial, entendiendo que existen diversas formas de clasificación que pueden coincidir en algunos casos, mientras que en otros son totalmente contradictorios. Esta dificultad no se resuelve únicamente con la interdisciplinariedad del análisis, sino con el desarrollo de una comprensión histórica concreta del proceso, que sea crítica en la reflexión de las subjetividades, de los discursos y del contenido ideológico que corresponde con la reproducción del sistema capitalista. De esta forma se pueden reconocer los aspectos de movilización que sean adecuados para la transformación política y económica de los trabajadores artesanales.

\section{Reflexiones políticas}

La organización internacional del trabajo debe constituir un escenario de justicia y libertad para el desarrollo de las habilidades creativas y humanas, siendo esto lo que Marx podría entender como trabajo creativo fuera de las formas de dominación del capital (MARX, 2011). En ese sentido, cuando se expone la relación entre las habilidades autónomas de producción, no es posible identificar el peso culturalista que ha cargado consigo la clase trabajadora de artesanos, y que por el contrario ha sido una camisa de fuerza para organizar políticamente su protección y salvaguarda de la vida en comunidad. Salir de la subordinación directa 


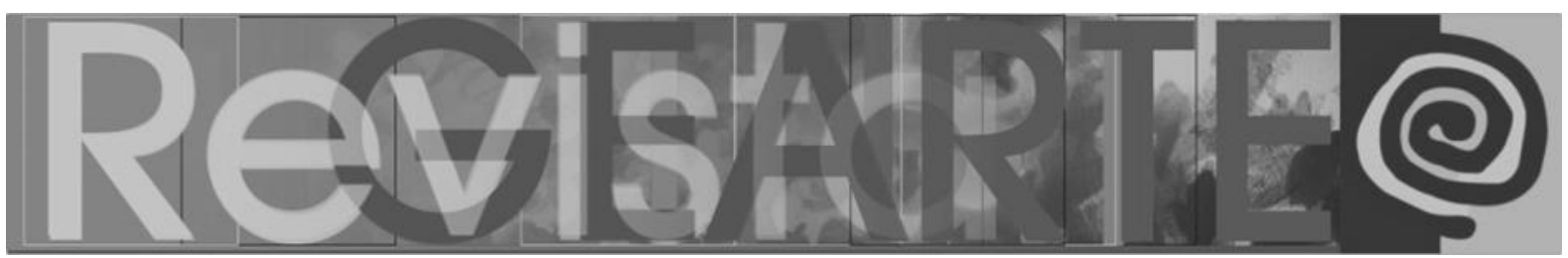

o indirecta del capital exige un reconocimiento crítico de la institucionalización de la artesanía como campo u objeto de conocimiento. No es posible reincidir en la fragmentación del trabajo si se consideran únicamente los valores culturales locales como eje de la organización política de los individuos.

En ese sentido debe existir una reflexión amplia de las posibilidades de organización de los trabajadores desde sus condiciones de resistencia y colectividad en respuestas amplias e intersectoriales de organización para alcanzar un control político de sus condiciones de producción tanto desde el Estado como desde las bases sociales. Uno de los problemas principales es no reconocer este proceso amplio de participación de los trabajadores en definir políticas públicas sectoriales que se mantienen al margen de cambios estructurales significativos en la población, y que por el contrario, en regímenes de democracia subordinada al mercado, terminan por validar prácticas de protección y promoción de las mercancías por encima de la población vulnerable.

De esta manera existe una doble relación entre el reconocimiento y fortalecimiento de la producción social alternativa al capitalismo, lo que se ha constituido desde los procesos de organización social y solidaria de los artesanos y artesanas, teniendo su auge principal en la organización sindicalizada y cooperativista de los trabajadores artesanales, llegando a reivindicar sus derechos como productores culturales. Sin embargo otra relación para generar esa integración a los procesos alternativos de producción debe consistir en el reconocimiento de la actividad artesanal como parte de una división social, técnica y simbólica del trabajo de forma internacional, lo que corresponde a un ejercicio de organización e identificación más allá de los límites de la profesión o del oficio, y más allá de las fronteras nacionales, pues es en la autonomía que se deriva de la afirmación de los artesanos y artesanas como trabajadores como podría conseguirse un proceso de integración de mayor fuerza en la protección y promoción de su bienestar. 


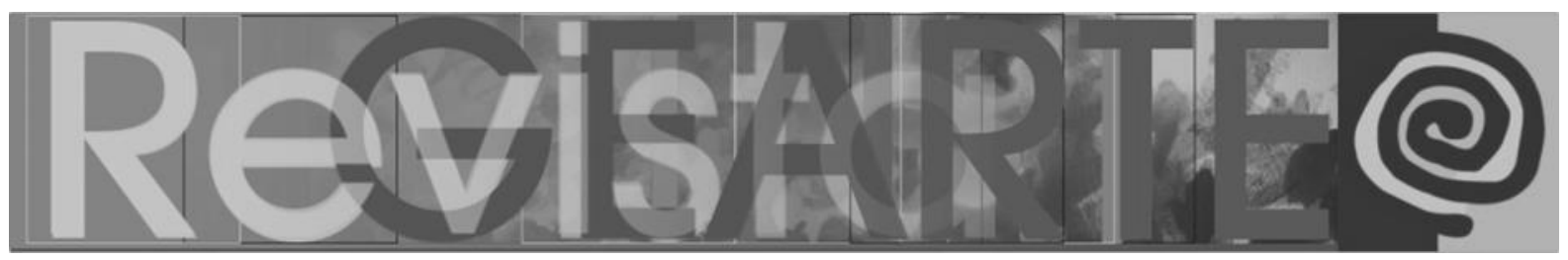

\section{Conclusiones}

La comprensión actual de la artesanía tiene que buscar superar la hegemonía cultural que pretende subordinar la expresión del saber hacer autónomo y comunitario a la acumulación del capital en escala internacional. La industrialización de la creatividad como mecanismo de transformación y clasificación de la producción actual que busca homogeneizar la diversidad local de los productores culturales debe tener un contrapeso en la reflexión crítica sobre la forma de intervenir políticamente para generar un bienestar a los individuos más allá de su dependencia a la producción de mercancías con valor cultural local. En ese sentido, comprender el desarrollo y génesis de la actividad artesanal requiere de su contextualización en el desarrollo desigual del capital. Por otro lado, aunque la producción académica sobre lo artesanal tenga un aumento significativo en el presente siglo, es necesario reconocer que las herramientas conceptuales sobre el trabajo artesanal tienen límites específicos en la reproducción ideológica dominante del capital de forma directa o indirecta, como tal toda intervención es una intervención política, y es desde allí como debe optarse por ser críticos con el desarrollo del trabajo artesanal.

\section{Referências}

AVELINO, C. O design, a arte e o artesanato deslocando o centro. Cadernos EBAPE, Rio de Janeiro, v. 5, n. 4, 2007.

CAMPOS, A. Racialización, racialismo y racismo un discernimiento necesario. Universidad de La Habana, 273, p. 184-199. 2012. Disponible en: https://www.academia.edu/6283861/Raci alizaci\%C3\%B3n_Racialismo_y_Racismo._Un_discernimiento_necesario. Acceso en: 12 fev. 2020.

CUNNINGHAM, S. From Cultural to Creative Industries: Theory, Industry and Policy Implications. Media International Australia, v. 102, n. 1, p. 54-65, 2002.

ENGELS, F. Revolución y contrarrevolución en Alemania. In: MARX, K. e ENEGELS, F. Obras Escogidas Tomo l. Editorial Progreso, Moscou. 1980. Disponible en: https://webs.ucm.es/info/bas/es/marx-eng/52rca/index.htm. Acceso en: 19 enero 2020.

FIGUEIREDO, M., et al. Empreendedorismo feminino no artesanato: Uma análise crítica do caso das rendeiras dos Morros da Mariana. RECADM, v. 14, n. 2, p. 110-123. 2015.

FREITAG, V. Entre arte y artesanía: elementos para pensar el oficio artesanal en la actualidad. EI Artista, v. 11, p. 129-143. 2014. 


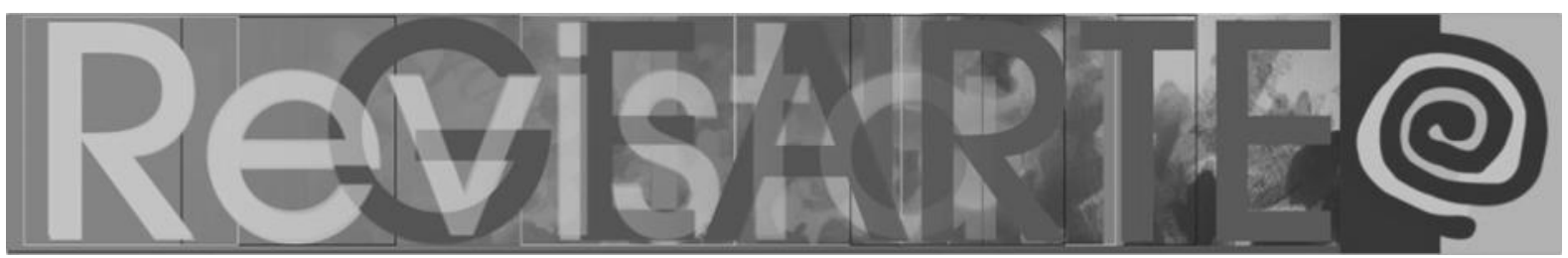

HOBSBAWM, E. Pierre Bourdieu, sociología crítica e historia social, New Left Review, v. 101, p. 41-52. 2016. Disponible en: https://newleftreview.es/issues/101/articles/eric-hobsbawm-pierrebourdieu.pdf. Acceso en: 4 enero 2020.

JURADO, G. S. B., AGUILAR, A. C. Q., \& JUAJIBIOY, J. C. J. Riesgos y tensiones de las marcas colectivas y denominaciones de origen de las creaciones colectivas artesanales indígenas. Apuntes. Revista de estudios sobre patrimonio cultural, v. 27, n. 1, 2014.

KELLER, P. Trabalho artesanal e cooperado: realidades, mudanças e desafios. Sociedade e Cultura, Goiânia, v. 14, n. 1, p. 29-40, 2011.

LOAIZA, G. Sociabilidad, religión y política en la definición de la nación: Colombia 1820-1886. Bogotá: Colección Bicentenario Universidad externado de Colombia, 2011.

MARX, K. Grundrisse: Manuscritos econômicos de 1857-1858. São Paulo: Boitempo, 2011.

MARX, K. Teorías sobre la plusvalía I, Tomo IV de El Capital. México: FCE, 1980.

MAZAUD, C. Entre le métier et l'entreprise Renouvellement et transformations de l'artisanat français. 2009. Tese (Doutorado em Sociologia) - Université de Nantes, Nates, 2009.

MEJÍA, D. La artesanía de México: historia, mutación y adaptación de un concepto. México: El Colegio de Michoacan. 2004.

MORA DE JARAMILLO, Y. Clasificación y notas sobre técnicas y el desarrollo histórico de las artesanías colombianas. Revista Colombiana de Antropología, v. 16, p. 283-354, 1974.

QUIÑONES, A. y BARRERA, G. Conspirando con los artesanos: Crítica y propuesta del Diseño en la artesanía. Bogotá: Editorial Pontifica Universidad Javeriana, 2006.

SCRASE, T. Precarious production: Globalisation and artisan labour in the Third World. Third World Quarterly, v. 24, n. 3, p. 449-461, 2010.

SENETT, R. The Craftman. London: Yale University Press, 2008.

UNDP, United Nations Development Programme. Creative economy report. Special Edition.

UNESCO, 2013. Disponible en: http://www.unesco.org/culture/pdf/creative-economy-report2013.pdf. Acceso en: 10 fev. 2020.

VEGA, D. El campo artesanal: Aporte teórico social y pedagógico. Tunja: Fundación Universitaria Juan de Castellanos, 2013.

ZARCA, B. L'artisanat. La plus populaire des classes moyennes? Vingtième Siècle, revue d'histoire, v. 37, p. $55-68,1993$.

\section{Daniel Roberto Vega Torres}

Possui graduação em Sociología - Universidad Nacional de Colombia - Bogotá (2010) e mestrado em Maestría en Historia - Universidad Pedagógica y Tecnológica de Colombia (2014). Doutor em Ciências Sociais Aplicadas da Universidade Estadual de Ponta Grossa e docente investigador - Fundación Universitaria Juan de Castellanos. Tem experiência na área de Sociologia da cultura, pesquisa em Educação.

ORCID: https://orcid.org/0000-0001-9951-157X

E-mail: dvega@jdc.edu.co

Currículo: http://lattes.cnpq.br/8158197997704522

Recebido em 31 de maio de 2019 Aceito em 28 de julho de 2020

VEGA TORRES, Daniel Roberto. Trabajo artesanal, artesanía e industrias creativas: reflexiones en torno a las 